\title{
Influence of Production Technology on Selected Polymer Properties
}

Josef Ponikelsky (0000-0001-9781-0832), Igor Zuravsky (0000-0002-8365-3431), Vit Cernohlavek (0000-00016816-1124), Jaromir Cais (0000-0002-1726-5326), Jan Sterba (0000-0002-2676-3562)

Faculty of Mechanical Engineering, J. E. Purkyne University in Usti nad Labem. Pasteurova 3334/7, 40001 Usti nad Labem. Czech Republic. E-mail: josefponikelsky@seznam.cz

In the article, the study of polymer properties is dealt with as a result of production technology on patterns, which were made by injecting, machining of the extruded profile and 3D printing. All samples were made from iglidur ${ }^{\circledR} \mathrm{J} 260$ material, and they were subsequently tested in order to find out properties of roughness, breaking strength, hardness according to Shore, friction coefficient and swelling. Furthermore, the samples were exposed to light microscopy, where material structure was studied, especially from the view of structure defects, distribution and shape of solid lubricants.

Based on the performed experiment, it can be stated that production technology affects some properties of the sliding bushing. Above all, properties of the sliding bushing were affected by 3D printing technology. The measured samples had the worst results with regard to roughness and swelling values. Conversely, the values acquired by measuring hardness were surprising as the $3 \mathrm{D}$ priting samples reached better results than the samples made by machining. The samples created by injection had the best results compared to others in all tests. The measured values corresponded to the values listed by the manufacturer. Machined sample of the extruded profile is mainly affected by the type of machining, but with consideration to the structure, it can be claimed that the extruded material has the same structure as an injected piece and its properties, with the exception of surface roughness, are on the same level.

Keywords: Polymer, Injection, Extrusion, Machining, 3D printing

\section{Introduction}

In the article, the study of the influence of used production technology on selected properties of the polymer made from sliding material iglidur ${ }^{\circledR}$ J260 was described. For the research purposes, the samples created by injection technology, machining of the extruded profile were used together with samples made by $3 \mathrm{D}$ printing method - FDM.

Tests were carried out on the samples to retrieve values of the coefficient of friction, roughness, hardness according to Shore's test, compressive strength, swelling, and structure analysis. Material iglidur $\AA$, which was developed by igus ${ }^{\circledR}$ company, is mainly used to produce sliding bushingss. Those are subsequently used in car, packaging, or textile industry.

The subject of the analysis were unanswered questions of the target customers when choosing sliding bushing for particular application. There are times when the user wants to use the sliding bushing igli$\operatorname{dur}{ }^{\circledR}$, but their requested dimensions do not correspond with the standard injected dimensions. For that case, there are three options. The production of molds for injection technology, which is based on high input costs to produce injection molds. This way is especially appropriate for mass production (thousands of pieces). This is where the best properties of the sliding bushing are reached. Igus ${ }^{\circledR}$ company carries out lab testing of each material which is developed. Acquired properties are provided by the producer online and in the catalogue. In 2018, 1140 milion pieces of iglidur ${ }^{\circledR}$ were made. The values measured in collaboration with the Department of Material Engineering will be compared with the manufacturing technologies of machining of extruded profile and 3D printing. During the production of extrusions, a rod material is created, which then has to be machined to fit the chosen dimension. Igus ${ }^{\circledR}$ company lists properties of the extruded profile which has the same properties as the injected semi-manufactured product. However, these properties do not have to be final since the following machining technology can significantly affect the properties of the selected material. The properties will be studied and compared with the properties of extruded profile and with the properties of other manufacturing technologies. The third option is $3 \mathrm{D}$ printing technology using the FDM method. This method is expected to have the worst properties caused by the manufacturing method itself. This method is very cheap and fast, so it is particularly useful for prototyping. The acquired properties can enable this technology to gain a broader scale of application such as for components designed for industrial purposes. The acquired properties will be compared with the properties of the injection and extrusion technologies [1-3]. 


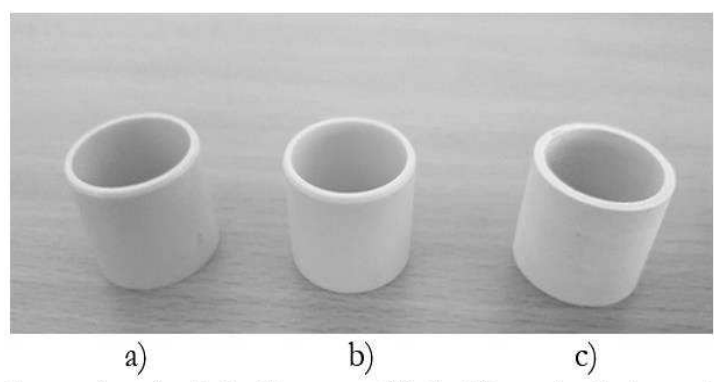

Legend: a) Injection molded b) extruded and machined c) 3D printing

Fig. 1 Sliding bushing example

\section{Methodology of samples production}

Igus $\AA$, the manufacturer of the sliding bushings, provided 10 samples of injected sliding bushings for this research. Moreover, they provided 10 samples of sliding bushings made by 3D printing, and a semi-manufactured rod made by extrusion, which was then machined to the requested dimensions of the sliding bushing in Hennlich inc. The manufacturing processes with the selected technology were preserved like in standard production of the sliding bushing.

\subsection{Injection technology of iglidur ${ }^{\circledR}$ material}

Since most produced parts are relatively small and have roughly the same shape, igus ${ }^{\circledR}$ invented more flexible modular system. Instead of creating a completely new mold everytime it is needed to produce a new special component, only liners (so called 'cavities') are made. In comparison with the main mold, which costs tens of thousands of Euros, the cavity starts at only $1,200 €$. The cavity igus $\AA$ usually consists of three parts - A, B, C. The Part A consists of the outer shape of bearings and a chamfer F1. The part B consists of a flange and 'nuzzles up' the component, Lastly, the part $\mathrm{C}$ and the core form inside diameter and a chamfer F4 (see Fig. 2). The injection process of the iglidur ${ }^{\circledR}$ material begins with the granulate of a raw material, which is melted and injected into an closed cavity. Once the material cools down, the cavity opens up and the new components can be extracted. It is also possible to create more components simultaneously. This procesudure makes the manufacturing process more effective, and it is used for mass-production. Company igus ${ }^{\circledR}$ does not provide more information regarding injection technology due to trade secrets. [1].
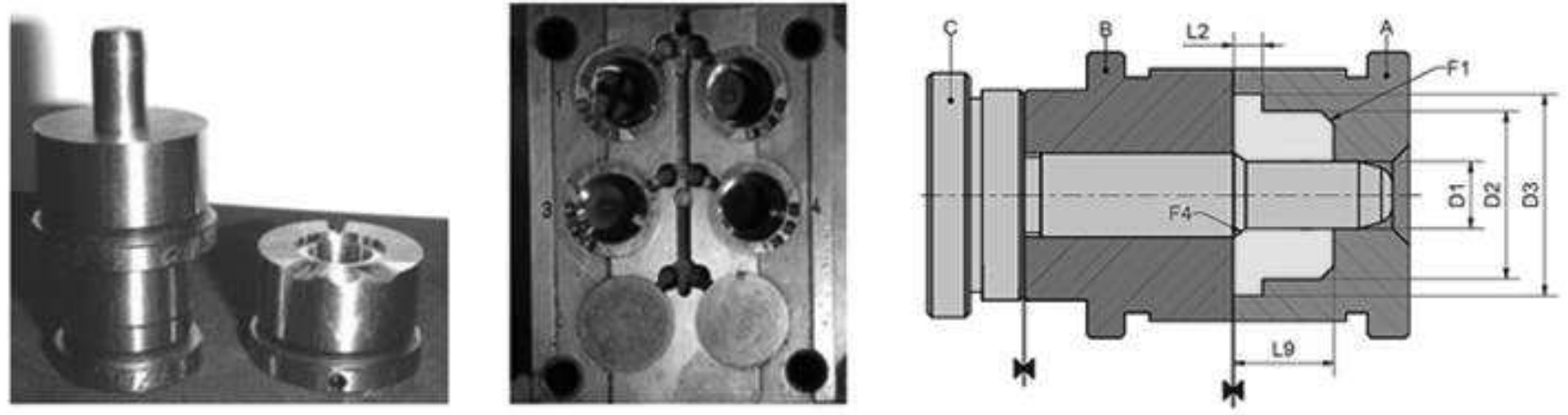

Fig. 2 Injection mold with cavities for the production of plain bearing

\subsection{Extrusion technology and machining of the igli-} dur ${ }^{\circledR}$ material

Plastic mixtures and additives are placed into the feeder and are melted in the heating zone of the extruder. The bolt presses the melted material through a nozzle and and shapes the iglidur ${ }^{\circledR}$ material (rods, pipes, boards). Extruded iglidur ${ }^{\circledR}$ is still very hot and it is necessary to cool it down in a bath before cutting it into requested dimensions. Uneven cooling after extrusion causes pressure in the centre, which leads to various problems during machining. For that reason, all materials have to go through the process of specific tempering, which eliminates the pressure. The extrusion is a very slow process, especially long lengths and diameters are often made only at the speed of $0.8 \mathrm{~m} / \mathrm{h}$. The extruded profile, which was provided by igus $\AA$ as a semi-manufactured rod with a diameter of $24 \mathrm{~mm}$ and $1 \mathrm{~m}$ length, was subsequently machined in Hennlinch Inc. on an EMCO MAXXTURN 45 machine. [1]

\subsection{Manufacturing using 3D printing - Fusion Depo- sition Modeling (FDM) Method}

During this method, the melted material is applied by the nozzle onto the model, where it solidifies. It is stored on the coil from where it is being withdrawn by the extruder in needed amount. First, the material enters the extrusion head in a form of a plastic wire, and subsequently is being fed through a heated nozzle by the feeding mechanism onto a work plate or previously applied layer. The layers are mathematically divided by the software with thickness between 0,127 and $0,254 \mathrm{~mm}$. Based on the shape, a supporting construction is created in places where support is needed. Heating temperature is theoretically just by $1{ }^{\circ} \mathrm{C}$ 
higher than the temperature of the material melting. The main movement takes place on the XY axes, the shift of the component vertically is often ensured by the working plate. In termally controlled head there are usually two nozzles. One of them is used for applying the model material, and the second one applies supporting material. The head applies the melted material through the nozzle with high accuracy into ultra- thin layers and on the printing desk. Once the nozzle drops the plastic, it immediately solidifies and connects with the previous layer. When the layer is finished, the building base drops by the layer thickness. Next, the thermally controlled head starts applying a new layer and repeats the process until the product is completely finished. [1].

Tab. 1 Print parameters

\begin{tabular}{|c|c|c|c|}
\hline Nozzle temperature & Bed temperature & 3D Printer & Printing details \\
\hline $270^{\circ} \mathrm{C}$ & $110^{\circ} \mathrm{C}$ & EVO-Lizer & Protected by IGUS trade secrets \\
\hline
\end{tabular}

\section{The Measuring method}

The experimental part is focused on the analysis of the influence of the manufacturing technology in relation to the properties of the sliding bushing made from the iglidur ${ }^{\circledR}$ J260 material, which was provided by the igus ${ }^{\circledR}$ company. In order to retrieve the values for comparison of the material iglidur ${ }^{\circledR}$ J260 properties, each manufacturing technology underwent measuring of roughness, pressure, coefficient of friction, hardness according to Sho-re, swelling and studying the structure using the light microscopy method.

Igus ${ }^{\circledR}$, the manufacturer of the sliding bushings, provided 10 samples of injected sliding bushings for this research as well as 10 samples of sliding bushings made by 3D printing and a semi-manufactured rod made by extrusion, which was subsequently machined to the requested dimensions of a sliding bushing in Hennlich Inc. The injected bushing, machined bushing and bushing made by 3D printing are displayed in Fig. 1. For better overview the samples were described based on their designation; see Tab. 1 .

Tab. 2 Description and designation of experimental samples

\begin{tabular}{|c|c|c|c|c|}
\hline Manufacturing technology & Sample designation & Inner $\varnothing(\mathrm{mm})$ & Outer $\varnothing(\mathrm{mm})$ & Length $(\mathrm{mm})$ \\
\hline Injection & V1 - V10 & 20 & 22 & 20 \\
\hline Extrusion+ machining & O1 - O10 & 20 & 22 & 20 \\
\hline 3D printing & T1 - T10 & 20 & 22 & 20 \\
\hline
\end{tabular}

\subsection{The Methodology of evalution of the experimen-} tal samples

The evaluation of the experimental samples will be examined from several points of view and by using different technologies, which are available in the labs of the Institute of technologies and materials at the Faculty of Mechanical Engineering. The evaluation of the samples will be examined using the following:

- Measuring of roughness of the surface: by measuring the roughness, the focus will be on how the manufacturing technology affects the inner and outer surface of the sliding bushing, and what differences are between the individual technologies.

- Measuring of compressive strength in pressure: On a bursting apparatus Insekt 100 there will be pressure tests on the sliding bushings on a cast iron broach until the deformation phase commences (burst). Each technology will have their compressive strength stated as well as the value difference among them.

- Measuring of coefficient of friction: 5 samples for each manufacturing technology will be tested on an apparatus Hommel Tester T8000. The roughness of the inner and outer diameter of the sliding bushing will be measured. It will be examined whether the results for the inner and outer surface are different and how the manufacturing technology affects the surface of the sliding bushing.

- Measuring of hardness according to Shore: There will be three samples in five different places for each manufacturing technology. The resulting values will be compared among the individual technologies and values provided by the igus ${ }^{\circledR}$ manufacturer.

- Measuring of swelling: The test will be carried out by submerging the samples of the sliding bushings into liquid of distilled water by representing one sample for each manufacturing technology. The samples will be firstly moved and measured and then submerged into the liquid for 168 hours and afterwards they will be remeasured and weighed. The focus will be on how much the inner and outer 
diameter, length and weight of the bushing change.

- Light miroscopy: The structures of sliding bushings for each manufacturing technology will be studied on confocal optical microscope Olympus LEXT OLS 3100. It will be determined whether a defect was formed in the structure and how the solid lubricants are distributed.

\section{Measuring results}

\subsection{Measuring of roughness}

Measuring of roughness was performed on a Hommel Tester T8000 apparatus in a specialised laboratory of accurate measurements of the Faculty of Mechanical Engineering. The measurement on the device is normalised and was performed according to the ČSN EN ISO 4287 norm. Overall, there were 30 measurements performed. There were five surface roughness measurements of the inner and five measurements of the outer diameter of the sliding bushing [4].

For the evaluation of the measurement parameters of roughness were used $-\mathrm{Ra}$ (average arithmetic deviation of the considered surface), $R_{z}$ (greatest height of the profile), $R t$ (total height of the profile). These parameters could help the end user in some situations during contruction of mechines with the given type of the sliding bushing iglidur ${ }^{\circledR}$. Arithmetic averages were calculated from the measured values for clarity of presentation of the results, see Tab. 2 [5].

Tab. 3 Measured values of Roughness

\begin{tabular}{|c|c|c|c|c|}
\hline $\begin{array}{c}\text { Tech- } \\
\text { nology }\end{array}$ & Surface & $\mathrm{Ra}[\mu \mathrm{m}]$ & $\mathrm{Rz}[\mu \mathrm{m}]$ & $\mathrm{Rt}[\mu \mathrm{m}]$ \\
\hline \multirow{2}{*}{$\mathrm{V}$} & Inner & 0.57 & 5.55 & 12.82 \\
\cline { 2 - 5 } & Outer & 0.44 & 3.814 & 6.59 \\
\hline \multirow{2}{*}{$\mathrm{O}$} & Inner & 2.49 & 15.2 & 23.99 \\
\cline { 2 - 5 } & Outer & 5.85 & 29.53 & 36.65 \\
\hline \multirow{2}{*}{$\mathrm{T}$} & Inner & 20.85 & 94.65 & 110.96 \\
\cline { 2 - 5 } & Outer & 20.97 & 99.2 & 120.09 \\
\hline
\end{tabular}

The first measurement was performed to determine roughness of the material of the sliding bushing for inner and outer surface of the sliding bushing by a normalised method on the Hommel Tester T8000 apparatus. Firstly, the measurement was done on the sliding bushing made by the injection technology, which is more common for sliding bushings. Next, the measurement was done on the sliding bushing made by machining of the extruded profile. Lastly, the measurement was done on the sliding bushing made by $3 \mathrm{D}$ printing with a FDM method. The measurement was always performed five times on the inner surface and five times on the outer surface. When comparing the measured values of the inner and outer surface for the injection and 3D printing technologies, it is apparent that inner and outer surface were not affected by manufacturing of the given technologies. The measured values of roughness converted into the arithmetic average were $R a=0.57 \mu \mathrm{m}$ for the inner surface and $\mathrm{R} a$ $=0.44 \mu \mathrm{m}$ for the outer surface. With the machining of the extruded material the inner surface was affected and its roughness worsened by about $3.36 \mu \mathrm{m}$ compared to the outer surface. The measured value of roughness of the surface and converted into the arithmetic average was $\mathrm{R} a=5.85 \mu \mathrm{m}$ for the inner surface and $\mathrm{R} a=2.49 \mu \mathrm{m}$ for the outer surface. This deterioration was probably caused by the change of the machining apparatus. For the bushings made by $3 \mathrm{D}$ printing, the values of roughness for the inner and outer surface were $\mathrm{R} a=20.97 \mu \mathrm{m}$ and $\mathrm{R} a=20.85 \mu \mathrm{m}$ respectively; these values were probably caused by the manufacturing technology of 3D printing. The applied layers cool down on surface much faster than underneath it. During such fast cool-down there is not enough time for them to merge, and that is why the nicked surface is formed. Igus ${ }^{\circledR}$ manufacturer does not list roughness of the surface for any of manufacturing technologies, so in that case it is impossible to compare them with the measured data.

\subsection{Measuring of compressive strength in pressure}

The principle of the test consisted in deformation of the sliding bushing by pressure equipment in order to set the compressive strength in pressure. There were five samples tested for each technology. Each sample was placed on a ČSN 11523 pin. During this test the sample was under the pressure until the moment of bursting. This burst can be considered the compressive strength in pressure. The test was performed on a universal bursting apparatus Insekt 100 and computing software LabMaster in a room temperature of $20^{\circ} \mathrm{C}$. The injection technology had the highest compressive strength. The destruction of the sample was observed when the values reached the range between $\mathrm{R} m=125 \mathrm{MPa}$ and $\mathrm{R} m=132 \mathrm{MPa}$. 3D printing had the second highest compressive strength in the range between $R m=121 \mathrm{MPa}$ and $\mathrm{R} m=126 \mathrm{MPa}$. The machined sample had the lowest values of compressive strength in the range between $\mathrm{R} m=99$ $\mathrm{MPa}$ and $\mathrm{R} m=110 \mathrm{MPa}$.

\section{a) Comparison between manufacturing technologies}

In the graph 1, there are curves of the compressive strength in pressure for the first measurement of each technology. It can be seen in the graph, the curve Injection 1 reaches the highest pressure resistence even to the point of compressive strength, which is $\mathrm{R} m=$ 129.8 MPa in this case. This resulted in destruction of the sliding bushing. The Extruded 1 curve respresents the sliding bushing that was made by machining of the 
extruded profile. During this measurement the measured value was $R m=102.8 \mathrm{MPa}$. In this case there was also a burst just like with the injected mold. The $3 \mathrm{D}$ print 1 curve reached $\mathrm{R} m=123.8 \mathrm{MPa}$ compressive strength in pressure. When comparing these curves, the order from the highest pressure resistance can be set as follows: injection, 3D printing and extrusion.

b) Comparison with the values provided by igus $\AA$ manufacturer

Igus ${ }^{\circledR}$ manufacturer mentions $\mathrm{R} m=50 \mathrm{MPa}$ for the compressive strength in pressure, however, the measured value of compressive strength in pressure in this experiment reached $\mathrm{R} m=129.8 \mathrm{MPa}$, and is thus about 2.5 times higher than the value provided by the manufacturer. This difference is caused by adding the coefficient of safety, which igus ${ }^{\circledR}$ company adds into the measured values. When it comes to the extruded mold, igus ${ }^{\circledR}$ manufacturer lists the same value as for the injected mold, ie. $R m=50 \mathrm{MPa}$. The average measured value in this experiment was $R m=102.8 \mathrm{MPa}$. Here the estimated measured value is two times higher than the values provided by the manufacturer. As for $3 \mathrm{D}$ printing, the manufacturer does not mention any value for compressive strength.

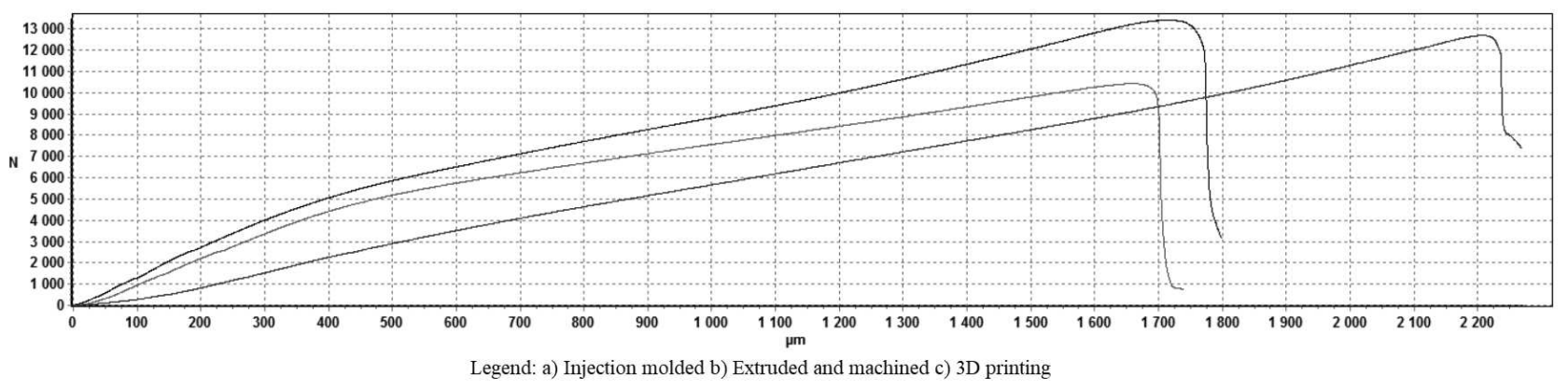

Graph 1 Pressure diagram (Force-displacement) for samples No. 1

\subsection{Measuring of friction coefficient}

Tab. 4 Measured values of coefficient of friction of material J260

\begin{tabular}{|c|c|c|c|}
\hline Technology & Sample & $\begin{array}{c}\text { Coefficient } \\
\text { of friction } \\
{[\mu]}\end{array}$ & $\begin{array}{l}\text { Standard } \\
\text { deviation }\end{array}$ \\
\hline \multirow{6}{*}{$\mathrm{V}$} & V1 & 0.075 & 0.013 \\
\hline & $\mathrm{V} 2$ & 0.063 & 0.006 \\
\hline & V3 & 0.061 & 0.006 \\
\hline & $\mathrm{V4}$ & 0.054 & 0.003 \\
\hline & V5 & 0.059 & 0.004 \\
\hline & $\begin{array}{l}\text { Average } \\
\text { arithmetic } \\
\text { value }\end{array}$ & 0.062 & 0.005 \\
\hline \multirow{6}{*}{$\mathrm{O}$} & O1 & 0.071 & 0.005 \\
\hline & $\mathrm{O} 2$ & 0.081 & 0.007 \\
\hline & $\mathrm{O} 3$ & 0.072 & 0.005 \\
\hline & $\mathrm{O} 4$ & 0.072 & 0.003 \\
\hline & O5 & 0.054 & 0.003 \\
\hline & $\begin{array}{c}\text { Average } \\
\text { arithmetic } \\
\text { value }\end{array}$ & 0.070 & 0.005 \\
\hline \multirow{6}{*}{$\mathrm{T}$} & $\mathrm{T} 1$ & 0.087 & 0.005 \\
\hline & $\mathrm{T} 2$ & 0.089 & 0.007 \\
\hline & T3 & 0.082 & 0.005 \\
\hline & $\mathrm{T} 4$ & 0.085 & 0.005 \\
\hline & T5 & 0.086 & 0.005 \\
\hline & $\begin{array}{l}\text { Average } \\
\text { arithmetic } \\
\text { value }\end{array}$ & 0.086 & 0.005 \\
\hline
\end{tabular}

The experiment took place on an apparatus provided by Bruker UMT/APEX Multi-Specimen Test System, in a specialised laboratory of accurate measurements of the Faculty of Mechanical Engineering. During this test a ball P/N BM110052, provided by Bruker company, was used with a $2.5 \mathrm{~mm}$ diameter and a load of $10 \mathrm{~N}$. The ball moved on a $10 \mathrm{~mm}$ track for 60 seconds and with velocity of $10 \mathrm{~mm} / \mathrm{s}$.

\section{a) Comparison of the coefficient among production technolo- gies}

The recorded values using the injection method are in the average arithmetic value of 0.062 with standard deviation of 0.006 . For the machining method the average arithmetic value recorded was 0.07 with standard deviation of 0.005 . For $3 \mathrm{D}$ printing the average arithmetic value recorded was 0.086 with standard deviation of 0.005 . When comparing the average arithmetic value for each recorded production technology, it can be seen that the injection method reached the best result followed by the machining and 3D printing method. The comparison of the recorded values can be seen in the Graph 2, where the curves of production technologies for measurements are displayed, and which are the closest to the average arithmetic values of the selected technologies.

b) Comparison with the values provided by igus $\AA$ company

The manufacturer lists the value of the friction coefficient for steel in the range between 0.06 and 0.20. All the recorded values were measured for each production technology in the range for the steel ball, so it corresponds to the values listed by the manufacturer for this type of material. 


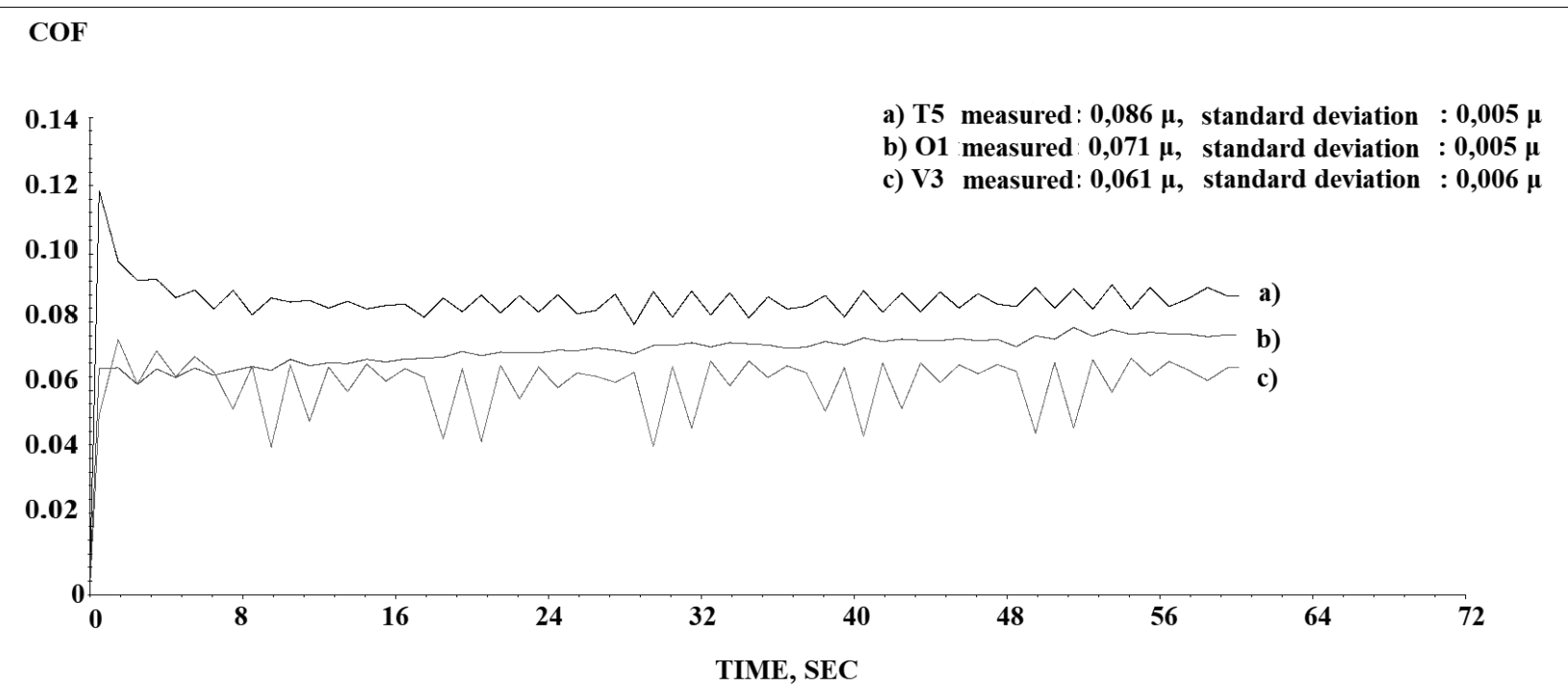

Graph 2 Friction coefficient curves of production technologies

\subsection{Measuring of hardness according to Shore}

Measuring of hardness according to Shore A., according to DIN 53505 was performer on a SHORE HARDNESS TESTER HT - 6510A apparatus. Overall, five samples for each production technology on three different places were measured, and afterwards the average arithmetic value was calculated.

Tab. 5 Measured values of hardness according to Shore

\begin{tabular}{|c|c|c|c|c|}
\hline $\begin{array}{l}\text { Tech- } \\
\text { nology }\end{array}$ & Sample & \multicolumn{3}{|c|}{$\begin{array}{c}\text { Hardness according } \\
\text { to Shore }\end{array}$} \\
\hline \multirow{7}{*}{$\mathrm{V}$} & $\begin{array}{c}\text { Number of mea- } \\
\text { surements }\end{array}$ & 1. & 2. & 3. \\
\hline & $\mathrm{V} 1$ & 87.9 & 88.1 & 87.2 \\
\hline & $\mathrm{V} 2$ & 86.9 & 87.5 & 88.3 \\
\hline & V3 & 85.4 & 86.4 & 84.3 \\
\hline & V4 & 84.3 & 87.4 & 83.4 \\
\hline & V5 & 85.9 & 85.2 & 88.2 \\
\hline & $\begin{array}{l}\text { Average arithme- } \\
\text { tic value }\end{array}$ & \multicolumn{3}{|c|}{86.4} \\
\hline \multirow{6}{*}{$\mathrm{O}$} & $\mathrm{O} 1$ & 86.4 & 86.7 & 85.5 \\
\hline & $\mathrm{O} 2$ & 87.4 & 86.1 & 85.6 \\
\hline & O3 & 86.9 & 85.7 & 85.1 \\
\hline & $\mathrm{O} 4$ & 84.3 & 88.2 & 84.9 \\
\hline & $\mathrm{O} 5$ & 85.9 & 88.7 & 88.1 \\
\hline & $\begin{array}{c}\text { Average arithme- } \\
\text { tic value }\end{array}$ & \multicolumn{3}{|c|}{86.3} \\
\hline \multirow{6}{*}{$\mathrm{T}$} & T1 & 75.6 & 77.3 & 78.7 \\
\hline & $\mathrm{T} 2$ & 74.7 & 78.2 & 76.8 \\
\hline & T3 & 74.9 & 78.4 & 75.9 \\
\hline & T4 & 76.9 & 75.2 & 76.3 \\
\hline & $\mathrm{T} 5$ & 76.7 & 75.3 & 76.6 \\
\hline & $\begin{array}{l}\text { Average arithme- } \\
\text { tic value }\end{array}$ & \multicolumn{3}{|c|}{76.5} \\
\hline
\end{tabular}

a) Comparison of hardness according to Shore among production technologies

For the injection and machining method the recorded values were roughly the same, and on average they reached 86.4 and 86.3 respectively. The samples made by $3 \mathrm{D}$ printing had the lowest values recorded reaching 76.5 on average.

b) Comparison with the values provided by igus $\mathbb{R}$ manufacturer

The manufacturer provides the following values of hardness according to Shore-the injected mold-77; extruded semi-manufactured product- 77; 3D printing filament-66. It can be then stated that the recorded values for all the production technologies are 10 units greater than what the manufacturer lists.

\subsection{Measuring of swelling}

The measuring of swelling of iglidur ${ }^{\circledR}$ material was performed through liquid submersion (distilled water) with the representation of one sliding bushing sample for each tested production technology. The samples were submerged for 168 hours in order to find out whether their inner and outer diameter, length and weight would change. The samples were remeasured and reweighed before and after extraction from the liquid. The recorded values are mentioned in Tab. 5 .

The recorded results show that when submerged in liquid and the sliding bushing is not in a moulded state, there is no internal stress being applied to the structure, and as a result there is no dimension change for the injection and machining of the extruded profile production technologies. The manufacturer of Igus ${ }^{\circledR}$ mentions maximum water absorption of $0.4 \%$ of its weight. In the case of the tested samples, it would mean weight increase of the injected mold by $0.01 \mathrm{~g}$. However, there was no weight change for the sample 
and it corresponds to the values provided by the manufacturer. With the 3D printed sample there was weight increase of $0.04 \mathrm{~g}$, which corresponds to the $1.7 \%$ of weight. The maximum weight change according to the manufacturer is $0.4 \%$ of weight, ie. $0.01 \mathrm{~g}$; in this case the recorded values do nott match the values provided by the manufacturer and exceed the given range. The weight increase of $0.04 \mathrm{~g}$ affected the growth of the inner diameter by $0.04 \mathrm{~mm}$ and the length by $0.02 \mathrm{~mm}$ compared to the dimensions prior to submersion.

Tab. 6 Measured values of swelling

\begin{tabular}{|c|c|c|c|c|c|c|c|c|c|}
\hline \multicolumn{2}{|c|}{ Technology } & \multicolumn{3}{|c|}{ Prior to submerging } & \multirow{2}{*}{$\begin{array}{c}\begin{array}{c}\text { Average arithmetic } \\
\text { value }\end{array} \\
20.2 \\
\end{array}$} & \multicolumn{3}{|c|}{ After submerging } & \multirow{2}{*}{$\begin{array}{c}\begin{array}{c}\text { Average arithmetic } \\
\text { value }\end{array} \\
20.2 \\
\end{array}$} \\
\hline \multirow{4}{*}{ V } & Inner & 20.19 & 20.20 & 20.21 & & 20.20 & 20.22 & 20.19 & \\
\hline & Outer & 23.13 & 23.16 & 23.09 & 23.13 & 23.15 & 23.11 & 23.12 & 23.13 \\
\hline & Length & 19.86 & 19.85 & 19.83 & 19.85 & 19.83 & 19.85 & 19.87 & 19.85 \\
\hline & Weight & 2.66 & 2.66 & 2.67 & 2.66 & 2.67 & 2.67 & 2.66 & 2.66 \\
\hline \multirow{4}{*}{$\mathrm{O}$} & Inner & 19.90 & 20.28 & 20.26 & 20.14 & 20.11 & 20.12 & 20.20 & 20.14 \\
\hline & Outer & 23.12 & 23.08 & 23.15 & 23.12 & 23.10 & 23.12 & 23.15 & 23.12 \\
\hline & Length & 19.77 & 19.74 & 19.75 & 19.75 & 19.76 & 19.76 & 19.75 & 19.75 \\
\hline & Weight & 2.59 & 2.6 & 2.59 & 2.59 & 2.60 & 2.60 & 2.59 & 2.59 \\
\hline \multirow{4}{*}{$\mathrm{T}$} & Inner & 19.65 & 19.49 & 19.64 & 19.59 & 19.62 & 19.64 & 19.63 & 19.63 \\
\hline & Outer & 23.36 & 23.38 & 23.39 & 23.38 & 23.36 & 23.39 & 23.39 & 23.38 \\
\hline & Length & 19.97 & 19.94 & 19.96 & 19.96 & 19.97 & 19.98 & 19.99 & 19.98 \\
\hline & Weight & 2.35 & 2.36 & 2.35 & 2.35 & 2.39 & 2.39 & 2.38 & 2.39 \\
\hline
\end{tabular}

\subsection{Studying of the structure using light microscopy}

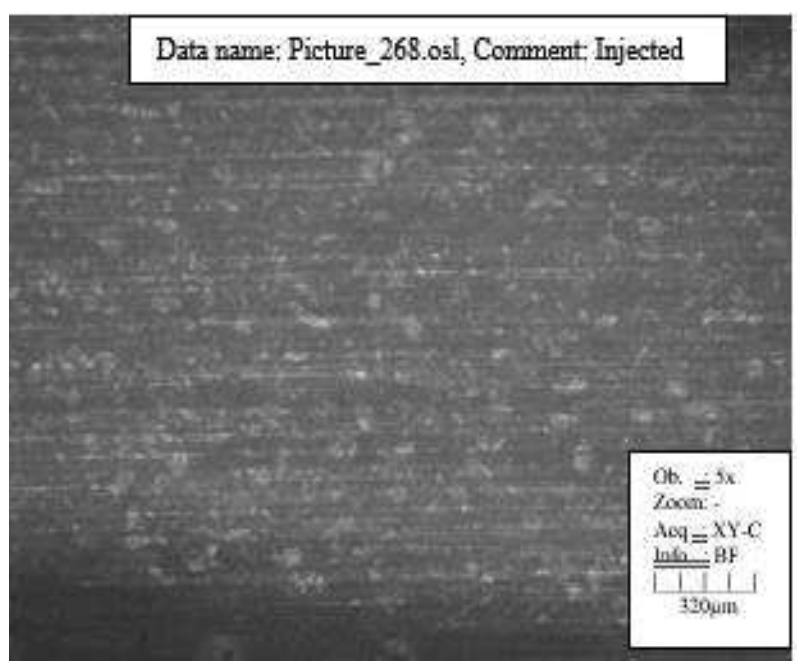

Fig. 3 Sample - Injected, Magnification 50x

The sample of the sliding bushing for each production technology was prepared in order to achieve better and most importantly safer manipulation. The preparation was carried out by a cold encapsulating method, where colourless casting binary methylmethacrylate resin Dentacryl (technical) with a relevant hardener was used. Mixing ratio was 100 volume portions of powder to 50 volume portions of the liquid. The marking of the sample encapsulated by the casting substance as well as the sample. The clean sample was placed in the mold, so that the area designated for further alteration was in contact with the bottom of the mold. The sample was encapsulated and left to harden for 24 hours. Furthermore, grinding was performed on a polishing apparatus SAPHIR 360. P102, P320, P600 and P1200 abrasive papers were used for grinding. The sample was continuously moved in the same direction to capture plane, and then the grinding was done in a direction perpendicular to the previous one. After the preparation of the cut, the structure of the samples was observed on a confocal optical microscope Olympus OLS 3100.

The structure of the injected mold of the sliding bushing can be seen with no internal defects in Fig. 3. Solid lubricants are distributed irregularly.

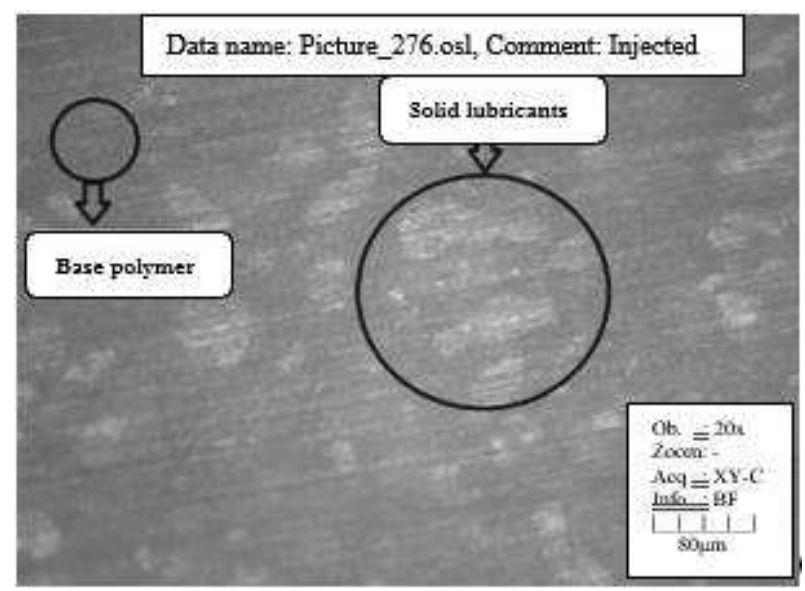

Fig. 4 Sample - Injected, Magnification 200x

The solid lubricants are highlighted in Fig. 4 as well as the base polymer. These particles have amorphous shape and measure approximately tens of micrometres. 


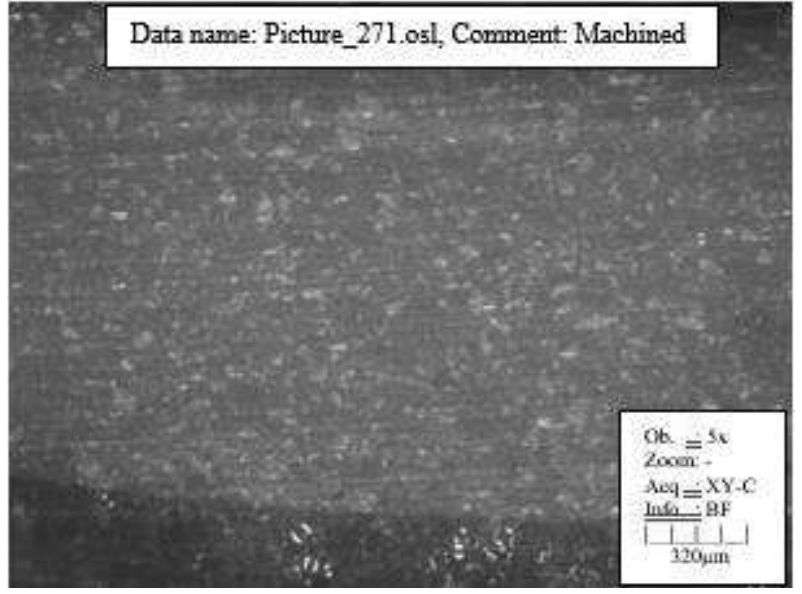

Fig. 5 Sample - Machined, Magnification $50 x$

The structure of the machined mold can be seen in Fig. 5 with no internal breach of the structure. The lubricants are evenly distributed and have the same shape as the injected mold.

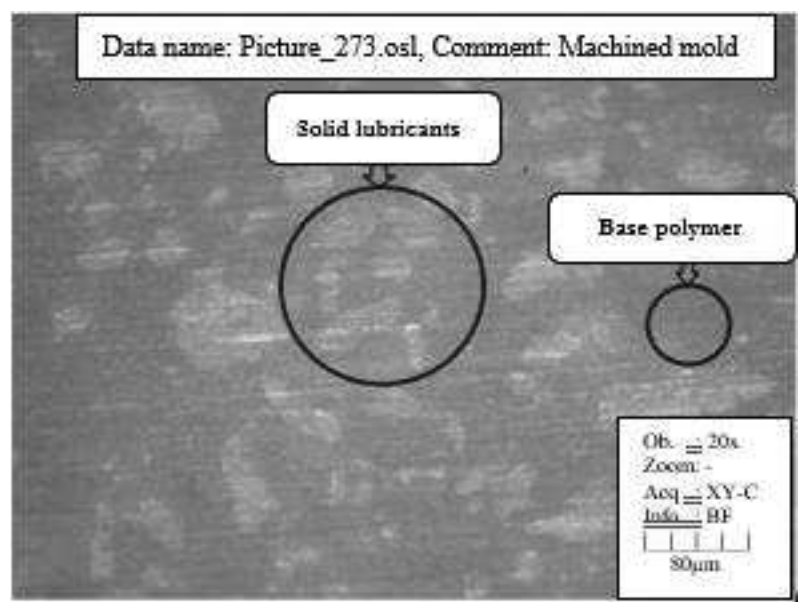

Fig. 6 Sample - Machined, Magnification 200x

The solid lubricants and base polymer are highlighted in Fig. 6. Since the semi-manufactured product was extruded, it is possible to observe the same structure as with the injected mold.

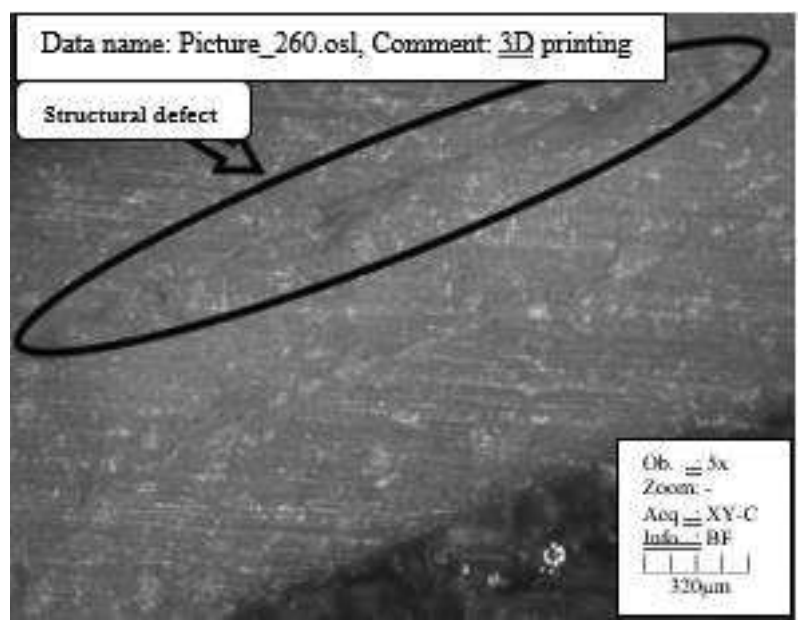

Fig. 7 Sample - 3D Printing cross section, magnification 50x
The structure of the sliding bushing made by 3D printing can be seen in Fig. 7, where pores can be observed within the structure. These were probably caused by application of the layer of the material and imperfect conjunction of the individual components.

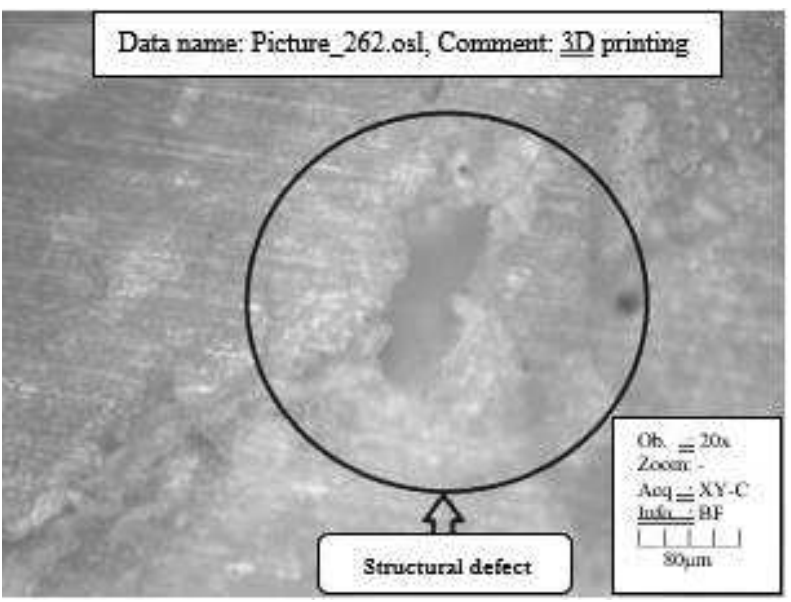

Fig. 8 Sample - 3D Printing cross section, magnification $200 x$

This pore disrupts the structure of the material, which can affect the properties of the sliding bushing. The occurence of this pore can cause higher absorption of the liquid, which results in dimension alteration and decrease in compressive strength. As tension can start to build up in the area of the pore, it can subsequently result in a mechanical failure. 200x magnification is displayed in Fig. 8.

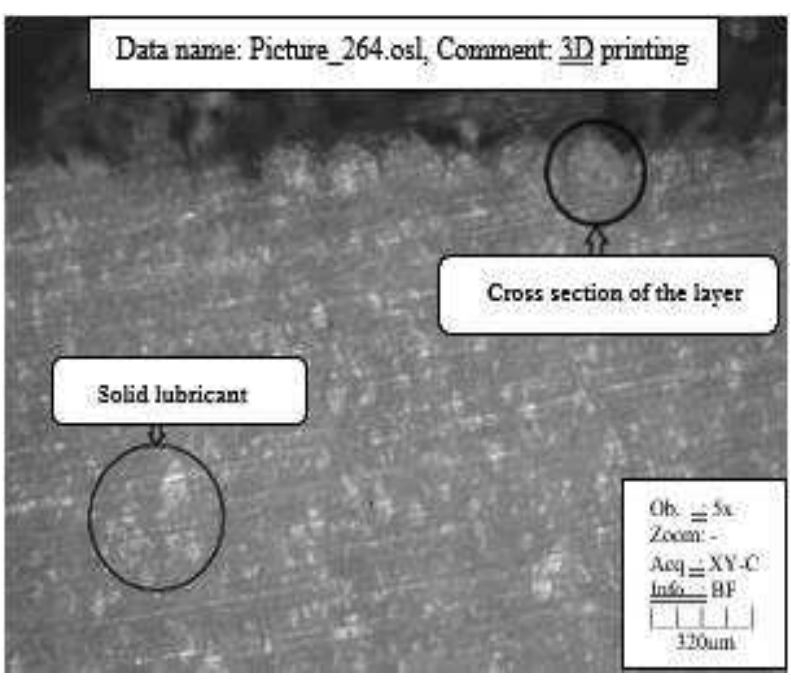

Fig. 9 Sample - 3D Printing horizontal cut, magnification $50 x$

On a lateral section in fig. 9, it can be seen that there was no cross-over of the layers on the surface of the bushing. This is probably caused by a rapid cooldown of the material. The material is fully interconnected underneath the surface. The solid lubricants have similar distribution compared to the structure of the injected and extruded samples. 


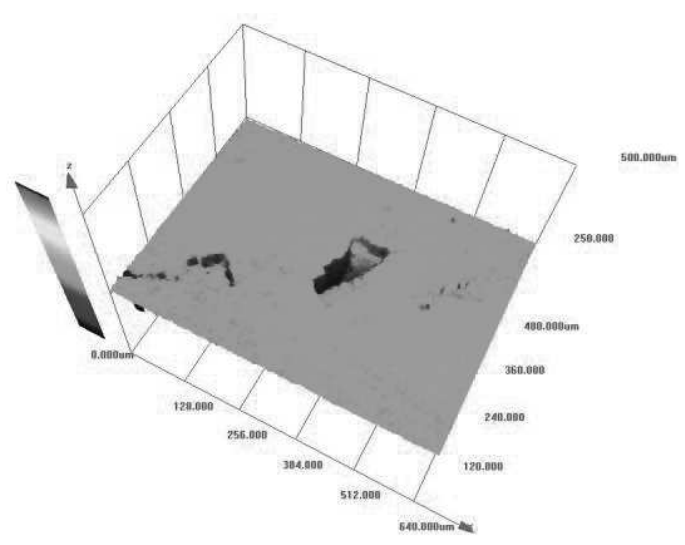

Fig. 10 Sample - 3D Printing, 3D Pore Model

The 3D model of the pore, which emerged on the sliding bushing made by $3 \mathrm{D}$ printing, can be seen in Fig. 10. This pore affected several layers under the surface. As a result, this pore can cause a decrease in compressive strength and greater swelling of the bushing.

\section{Discussion and conclusion}

The purpose of this research was to study properties of a polymer on samples made by the following production technologies-injection, 3D printing, and machining of the extruded profile. The samples, which were made from iglidur ${ }^{\circledR}$ J260 material in a shape of a sliding bushing, underwent individual measurements, and the properties were compared with the values provided by the manufacturer.

Based on the values obtained by roughness measuring of the samples of all three production technologies, it can be said that production technology affects roughness of the surface significantly. The injection technology showed the best values with the average arithmetic value of roughness, which were $\mathrm{R} a=0,57$ $\mu \mathrm{m}$ and $\mathrm{R} a=0,44 \mu \mathrm{m}$ for the outer and inner surface respectively. The machining technology was the second best, where the average arithmetic values were $\mathrm{R} a=2,49 \mu \mathrm{m}$ and $\mathrm{R} a=5,85 \mu \mathrm{m}$ for the outer and inner surface respectively. In this case it is possible to observe a difference between the roughness of the inner and outer surface caused by changing the apparatus. As expected, 3D printing manufacturing displayed the worst results of the surface roughness. The average arithmetic values were $\mathrm{R} a=20,85 \mu \mathrm{m}$ and $\mathrm{R} a$ $=20,97 \mu \mathrm{m}$ for the outer and inner surface respectively.

The measuring of compressive strength in pressure was performed on five samples for each production technology, and the average arithmetic value was calculated for the individual technologies. The samples made by the injection technology had the highest strength of $F_{\max }=13148,6 \mathrm{~N}$ and $\mathrm{R} m=129,8$
MPa with ductility of $A=5,92 \%$. The samples made by $3 \mathrm{D}$ printing technology had the second highest strength of $F_{\max }=12549,2 \mathrm{~N}$ and $\mathrm{R} m=123,8 \mathrm{MPa}$ with ductility of $A=3,7 \%$. The samples made by machining of the extruded profile had the lowest strength of $F_{\max }=10393,6 \mathrm{~N}$ and $\mathrm{R} m=102,8 \mathrm{MPa}$ with ductility of $A=6,18 \%$. This measurement revealed by comparing the results with the manufacturer's values that the manufacturer who mentions the compressive strength in pressure of $50 \mathrm{MPa}$ also adds the safety coefficient in their values, which is approximately 2,5 .

Measuring of the coefficient of friction revealed that all the measured values correspond with the range listed by the manufacturer, which is between 0,06 and 0,20 . The injected mold recorded the best results, where the average arithmetic value was 0,062 and the standard deviation was 0,005 . The machining method showed the average arithmetic value of 0,070 and the standard deviation was 0,005 . 3D printing production had slightly worse results with the average arithmetic value of 0,086 and the standard deviation was 0,005 .

Measuring of hardness according to Shore recorded values of 86,4 and 86,3 for the injection and machining technologies respectively.

Measuring of swelling revealed after 168 hours of the samples being submerged in liquid that the samples made by the injection technology and machining of the extruded profile did not display any dimension or weight changes. The sample made by $3 \mathrm{D}$ printing changed its weight by $1,4 \%$ increase, ie. $0,04 \mathrm{~g}$, and its inner diameter increased by $0,04 \mathrm{~mm}$ and got $0,02 \mathrm{~mm}$ longer compared to the dimensions prior to submersion. This measurement proved that $3 \mathrm{D}$ printing affected the material and changed its absorbability, which resulted in the increase of the inner diameter.

Light microscopy was carried out to gather information about structural defects and the shape of solid lubricants. The samples made by injection and machining of the extruded profile technologies did not show any defects in the structure. The structure was continuous, and the solid lubricants had amorphous shape and were irregularly distributed. The sample created by $3 \mathrm{D}$ printing showed pores in the structure, which were probably caused by $3 \mathrm{D}$ printing production technology. The applied melted material began to cool down quickly and the structure did not have enough time to interconnect. These pores which were created in the sliding bushing can affect its properties, especially strength, toughness, and swelling of the material. The solid lubricants had similar distribution and shape as the previous two production technologies.

The incentive for this research was the problematic of choosing technology for production of a sliding bushing with respect to the properties of the iglidur ${ }^{\circledR}$ J260 material. This study did not concern the economic aspect of the selected technologies, so the choice of the most suitable technology for sliding bushing 
production only takes into account the change of properties among the particular technologies.

Based on the research, it can be stated that production technology can influence some particular properties of a sliding bushing. 3D printing technology affected the properties of a sliding bushing the most. The roughness and swelling values were the worst on the measured samples. Conversely, the recorded values of strength were quite surprising, where the samples made by $3 \mathrm{D}$ printing reached better results than the ones made by machining. The samples made by injection came on top in all tests. The recorded values corresponded with the values listed by the manufacturer. The machined sample of the extruded profile is majorly affected by the machining method itself, but with respect to the structure it can be said that the extruded profile has the same structure as the injected mold, and its properties are on the same level with the exception of roughness of the surface.

\section{References}

[1] Katalog společnosti igus ${ }^{\circledR}:$ Dry-tech ${ }^{\circledR}$ kluzná pouzdra (2015), MAT0070571.8. 01/2015

[2] KREBS, J. (2001). Teorie appracování nekovových materiáliu. Liberec: TU v Liberci, $250 \mathrm{~s}$. ISBN 80-7083-449-8
[3] DUCHÁČEK, V. (2005). Polymery - výroba, vlastnosti, zpracování, pourizití 1. vyd. Praha: Vysoká škola chemicko-technologická v Praze, s. 354. ISBN 80-7080-241-3.

[4] KUTA, A. (1999). Technologie a zař̌zení pro apracováváni kauínkiu a plastù. Vyd. 1. Praha: Vysoká škola chemicko-technologická, ISBN 80-7080367-3.

[5] MLEZIVA, J. (1993). Polymery - výroba, struktura, vlastnosti a pourìití. Sobotáles: 1st ed. Praha, ISBN 80-901570-4-1.

[6] VAŠINA, M., PÖSCHL M., ZÁDRAPA, P. (2018). A Study of Significant Factors Affecting Viscoelastic Damping Properties of Polymer Material. Manufacturing Technology, vol. 18, no. 3, pp. 523-529, ISSN 1213-2489.

[7] MARKOVIČOVÁ, L., ZATKALÍKOVÁ, V., VAŠKO, A. (2016). Accelerated Aging of Polymeric Composites in Laboratory Conditions. Manufacturing Technology, vol. 16, no. 5, pp. 10331037, ISSN 1213-2489. 